\title{
Risk dimensions of a vertical Chinese expansion in the Greek tourism sector: the Chinese side
}

\author{
Angeliki N. Menegaki* \\ Department of Economics and Management of Tourist Businesses, \\ TEI Stereas Elladas, \\ Amfissa, 33100, Greece \\ Email: amenegaki@teiste.gr \\ and \\ Economic Analysis and Policy Lab, \\ School of Social Sciences, \\ Hellenic Open University, \\ Patras, Greece \\ *Corresponding author
}

\section{Giorgos M. Agiomirgianakis}

Economic Analysis and Policy Lab,

School of Social Sciences,

Hellenic Open University,

Patras, Greece

Email: gmagios@otenet.gr

\begin{abstract}
The soaring Chinese outbound tourism, the agglomeration of Chinese investment in Greece and the attractiveness of Greece as a Mediterranean tourist destination jointly generate motives for Chinese entrepreneurs to invest in the Greek tourism sector. However, to the best of our knowledge, a risk analysis of Chinese vertical integration in tourist businesses has received a rather limited research attention. The purpose of this paper is to investigate Chinese investment in the Greek tourism sector via a multiple dimensional risk analysis involving economic, environmental, social and cultural risks that could be possibly faced by prospective Chinese tourism investors in Greece. This paper will help Chinese public agents in reducing asymmetric information associated with an expansion in Greek tourism market.
\end{abstract}

Keywords: Chinese tourism; Greece; industrial tourism; risk; vertical integration; China.

Reference to this paper should be made as follows: Menegaki, A.N. and Agiomirgianakis, G.M. (2019) 'Risk dimensions of a vertical Chinese expansion in the Greek tourism sector: the Chinese side', Int. J. Decision Sciences, Risk and Management, Vol. 8, No. 3, pp.149-171.

Biographical notes: Angeliki N. Menegaki holds a $\mathrm{PhD}$ in Economics from the University of Stirling, UK and an MA in Economics and Finance from the University of Leeds, UK. In 2011, she also completed a degree in Turkish Language and Culture in DUTH. Her new affiliation is the Department of Economics and Management of Tourist Businesses in TEI STEREAS ELLADAS, Greece, where she is also the head of department. She teaches micro and macro modules with a focus on tourism economics. 
Giorgos M. Agiomirgianakis is a Professor at the Business Administration Programme of the Hellenic Open University (HOU). He has served as Dean of the School of Social Sciences (2008-2012) and Academic Director of the Business Administration Undergraduate Programme for nine academic years. He has served (2006-2010) as the President of the European Economics and Finance Society. He has 29 years teaching experience in higher education, both in Greece and Britain (Hull, Solent, Brunel, City). From 1997 to 2001 he taught at City University of London. He was member of the National Network of Environmental Education 'Tourism and Environment' of the Ministry of Education (2006-2011). He was, also, the coordinator of the Thematic Unit B-3 and G-3 of the Forum for Tourism Education and Training of the Ministry of Tourism Development (2007-2008).

\section{Introduction}

China has achieved a dynamic entrepreneurial presence in Greece. Since the first big step accomplished through the Chinese flagship investment worth of $€ 1.1$ billion, namely the COSCO investment in Piraeus seaport in 2008 and 2016, additional projects have followed. The Chinese purchase of a $24 \%$ stake of the Greek Independent Power Transmission Operator, worth $€ 320$ million, and the keen investment interest of the Chinese side for renewable energy sources in Greece, telecommunications and real estate development (the $€ 7$ billion worth project for the development of the former Athens Airport-Hellenikon), all constitute evidence that the Chinese are a promising group of investors that will expand to additional fields of the Greek economy with plausible mutual benefits for both the Greek and the Chinese sides. Furthermore, about 850 Chinese citizens have bought property in Greece through the Golden Visa programme, which grants them the Greek nationality provided that they spend about $€ 550,000$ on buying property.

The aggregate volume of Chinese investment in Greece is estimated to be around $€$ 585-840 million depending on the source and type of data one is looking at. For example the former number has been estimated as total volume of Chinese FDI (Foreign Direct Investment), while the latter has been estimated as FDI on a balance of payment basis. Based on data from the Greek embassy in Beijing, Chinese FDI in Greece was stated to be $\$ 1.6$ billion (or $€ 1.4$ billion) in 2017 . Also, the American Enterprise Institute (AEI) has estimated that the accumulated volume of Chinese investment in Greece, between 2005-2017, was $€ 6.7$ billion.

Given the aforementioned investment size, Chinese entrepreneurs should make the most of an agglomeration effect formed by them in Greece. This follows from the fact that initial investments create network effects and economies of scale for the rest of the investments that follow. Furthermore, these effects will be easier to materialise in a country which is as small as Greece. The tourism industry will be highly benefited from this agglomeration situation. Indeed, the benefits of COSCO investment are already obvious in this respect, since after September 2017, when the first chartered flights began between Beijing and Athens, cruise travels also started from Piraeus port towards other European destinations, thus showing another role that can be played from Greece, namely the tourist cross-roads of Chinese travellers to Europe. 
According to Skivalou and Filippidi (2015), 82 million Chinese tourists travelled the world in 2012 and only 3 million visited Europe. The numbers have kept growing every year, and will continue to do so, given that only $5 \%$ of Chinese nationals have a passport, while their government is issuing about 10 million new travel documents every day (Majendie, 2018). Nevertheless, Chinese people are responsible already for more than one fifth spent by outbound tourists worldwide. According to Skivalou and Filippidi (2015), their numbers in Greece have increased by $1,148 \%$ in the period $2010-2017^{1}$. Greece is the seventh most popular European destination for Chinese tourists in 2017, with two out of three of them belonging to high-income tourists who spend $€ 5,679$ per trip or $€ 931$ per day (Skordas, 2018). According to Cooper et al. (2006), the percentage of Chinese people who had a high enough income to enable them participating in outbound tourism was small, only 50 million, although the Chinese people were 1.3 billion in population at that time. Even if there is a small increase in the Chinese population segment that can afford outbound tourism, this is regarded as a huge number of outbound tourists. Moreover, based on Vanhove (2018), nowadays 20\% of large hotel chains, worldwide, are Chinese, $15 \%$ are European and the rest $65 \%$ are American.

In a more comprehensive piece of research, Lin et al. (2015), estimate long run income elasticity of Chinese tourists for all destinations to range from 0.406 to 1.785 , while the own price elasticity to vary from -9.490 to -0.152 and they have identified five categories of destinations. The fifth category also encompasses two European country destinations, Germany and Italy, which are described as price inelastic. Furthermore, the study states that Chinese tourists like combining multiple destinations in a single tourist trip and this is facilitated with Schengen agreement. Other studies have studied specific tourist destinations such as Australia (Pham et al., 2017) and Thailand (Utong et al., 2015). Pham et al. (2017) find high income elasticity together with high price elasticities for Chinese tourism towards Australia. Thus, their policy results advise that keeping ground and travel costs low, will also keep high the Chinese travelling growth rates to Australia. The latter which is a study by Untong et al. (2015) has shown that Chinese tourists respond less to a change in Thailand's prices (as a tourist destination) than to changes in competitor's prices. No elasticity studies have taken place for Greece. Albeit the number of these elasticity studies is very limited, we conjecture that results for Greece destination could be similar to the ones for Germany, because they are close markets, within the European Union (EU) and Schengen agreement territory.

The picture with flourishing Chinese tourist numbers described above generates two major questions: One is whether Chinese tourist numbers can fit in a market such as Greece, defined by a small geographical location seething already with tourists (other than Chinese in its majority) with a number equal to triple the size of the Greek population and a bounded hotel capacity. Second, what are the risks for relevant Chinese business vertical integration? Vertical integration is generally acknowledged to smooth uncertainty and pursue greater profit internalisation. Fan et al. (2017) report that Chinese companies in the 2000s have been more vertically integrated than the US companies in the 1990s'. According to their research, Chinese companies are more integrated in their home country when they are found in provinces with weak protection for property rights and are also characterised by slow reforms and corrupted and bureaucratic governments. Thus, this fact reveals that Chinese companies have a tendency towards vertical integrations and this business situation that is most likely to develop in the Greek tourism sector, too. 
The risk analysis offered in the current paper is of a qualitative nature, since data on individual Chinese companies are not available publicly. This paper attempts to throw light on as many aspects as possible which may be of some interest to Chinese investors in learning about Greece as an investment hub. The structure of the paper is as follows: after this introduction (Section 1), Section 2 presents a background information and stylised facts about Chinese tourists and Greece as a tourist destination for them. Section 3 discusses the risks pertinent to Chinese vertical integration and attempts to decrease the asymmetric information. Section 5 contains concluding points and policy implications.

\section{Chinese tourists in Greece: history and stylised facts}

This section contains background material and stylised facts about Chinese tourists and about Greece as a destination country, which also offers the ground for vertical integration.

Table 1 Hotel and bed distribution across Greece

\begin{tabular}{lcccc}
\hline Hotel stars & Number of hotels & Number of rooms & Number of beds & $\begin{array}{c}\text { Percentage of } \\
\text { hotels }\end{array}$ \\
\hline $5^{*}$ & 496 & 74,884 & 153,132 & $5.10 \%$ \\
$4^{*}$ & 1,485 & 107,805 & 211,064 & $15.20 \%$ \\
$3^{*}$ & 2,515 & 96,129 & 186,056 & $25.70 \%$ \\
$2^{*}$ & 3,900 & 108,383 & 204,193 & $39.82 \%$ \\
$1^{*}$ & 1,387 & 26,926 & 51,600 & $14.18 \%$ \\
& 9,783 & 414,127 & 806,045 & $100 \%$ \\
\hline
\end{tabular}

Source: Hellenic Institute of Tourist Research and Forecasting (2018)

Organised tourism started in Greece around 1895 with the establishment of a non-for profit organisation called the 'cycling society'. Since then, more societies were developed, which dealt with the organisation of excursions and short trips (Konsolas, 2002). Tourism has started increasing slowly in Greece after 1950 with about 33,000 tourists. Greece had just recovered from the wounds of the Second World War and the civil wars that afflicted it for quite some time. Tourist businesses at that time were small with no expertise on the management and promotion of the tourist good. Tourism in Greece started increasing significantly after 1960 with 399,400 tourists. After 1997 and up to 1991, Greece had turned into a mass tourism destination with a tourist preference focused on major archaeological monuments such as the Acropolis and Parthenon in Athens. After 1970, this trend changed with international tourists starting their visits to the islands of Greece and its beaches. Thus, a new tourism model has been established with a focus on 'sea and sun' holidays. The tremendous tourist arrivals outbreak during these years (in 1970 tourists were about 1.6 million, in 1980 this number increased to 5.2 million and in 1990 it exploded to 8.9 million) led to an unplanned tourist development which harmed the landscape and the environment (Kostopoulou, 2017). Thus, nowadays tourist arrivals to Greece count as much as triple the size of the Greek 
population. They were about 27 million in 2017 with a forecast estimation of about 30 million in 2018 according to SETE, the Greek Tourism Confederation. In Greece, there is also high seasonality of tourism with $43 \%$ of the nights spent annually to occur in July and August (Eurostat, 2018). Moreover, Greece has a capacity of 9,370 hotels with 788,553 beds totally. These are allocated in Table 1, according to their category.

The above numbers reveal a high hotel capacity in Greece when they are compared with the largest hotel chain in the world, Marriott which counts 5,700 hotels and 1.1 million rooms in more than 110 countries (Fortune.Greece, 2016). Up to date, in Greece, the largest hotel chain is the 'Grecotel hotels and resorts' with more than 30 luxury hotels in Greece and in co-operation with TUI Group, which is the largest tour operator in Europe with annual turnover equal to $€ 18.5$ billion in 2017 increased by $11.7 \%$ compared to the previous year. In 2017, TUI Group served about 20 million guests in 380 hotels and more than 100 destinations. It has a fleet of 150 aircrafts, 16 cruise ships and 67,000 employees (TUI Report, 2017). In Greece, there are about 3,800 travel agents and tour operators with annual revenue equal to $€ 12.7$ million (ECTAA.org, 2016). About 24,000 people were employed in these offices in 2014.

In a market environment as the above, it is reasonable for businessmen to consider integration opportunities. Tour operators have engaged to both horizontal and vertical integration in the European market and Greece. Larger tour operators have taken over smaller ones (horizontal integration) and some others have integrated vertically by integrating airlines, hotel chains, buses and travel agent offices. In 1999 there were ten large tour operators in Europe which have now become six, but with a much larger market share. This has generated oligopolies which exercise a lot of pressure to small businesses about their prices and market share. Tourist operators are also criticised for weakening local businesses, for securing capacity only for large hotels, for contributing to air pollution, to waste production and to the exhaustion of natural resources and the offering of a homogeneous standard product which does not take into account individual preferences and the special needs of tourists. Foremost, tourist operators are blamed for not allowing the travel destination to enjoy any financial and economic benefits from tourism, not allowing the development of alternative tourism, for negatively affecting local commercial businesses and for worsening the quality of tourist product, because they exercise much pressure for price reductions.

In Europe and Greece two large tour companies operate: TUI Travel Group and Thomas Cook Travel Group (operating in Central and Northern Europe mostly). They serve 30 different countries in Europe and 55 million tourists with a portfolio of 230 brands. Thomas Cook has an annual growth rate of $2.8 \%$ from its ten most prominent markets and an earnings growth rate of $2.1 \%$. In some destinations such as Crete and Rhodes, about $95 \%$ of the tourists have booked their holidays through tourist operators. As far as the TUI Group is concerned, this tour operator distributes the largest percentage of European tourists visiting Greece. Its subsidiary, TUI Hellas, has 22 branches in Greece. A possible Chinese tour-operator would have the advantage of a single emitting market, while the European tour-operators work in many different countries and are confronted with different legislations and risks. Other big tour operators which have a large portion of the tourist market in Greece are FTI Touristik (Germany), Nouvelles Frontiers (France) and Alltours (Germany). 


\subsection{The generation and evolution of Chinese tourism}

The communist regime in China had imposed strict control on the daily lives of Chinese people, particularly during the period of 1966-1976. After 1978, the Chinese government focused on the market economy. This resulted in significant GDP growth rates as well as more extroversion and openness of China to the outside world. Tourism was one way for Chinese people to get to know the rest of the world. However, in 2009, group tours started declining, giving their position to more independent tourism. Nowadays, Chinese tourism is a more 'in depth' type tourism, whereby tourists are looking for experiences in fashion, music, gastronomy and other life fields. Chinese tourists have a lot of access to information and this makes their tourist choices more sophisticated.

About 120 million outbound tourists travelled from China in 2014. From them, 6 million have travelled to Europe. In the last two years, Chinese tourists to Greece have been more than 100,000 yearly. This is a small figure compared to the 120 million aforementioned travellers. Foremost, Chinese tourists have overcome American and German tourists in the tourist expenditure they contribute. Chinese tourists do not have much time available for tourism and they typically choose to travel during February, May and October when they celebrate national holidays (Papadimopoulos, 2017). It should be noted that this is a rather convenient fact which can contribute towards balancing the heavy seasonality of Greek tourism in the summer months, without crowding out European or American tourists and allowing much higher numbers of Chinese tourists to visit Greece without creating new hotel capacity. The capacity of 806,045 beds could be fully exploited by the 170,000 Chinese tourists coming to Greece in the idle period, namely between mid November to mid April or May (Note: The tourist season in Greece typically starts with the advent of tourists coming to celebrate the Catholic Easter).

In building up the profile of the Chinese tourist, we note that since 2009, outbound tourists in China are young or middle-aged people (ages 25-44 are about $60 \%$ ) with high incomes $(22.81 \%$ of them earned from $¥ 5,001-8,000$, i.e., this is equivalent to $€ 628-1,004$ Yuan) and a good education (more than half held a bachelor's degree), who travel abroad for the first time in their lives (61\%), with the aim mostly of sightseeing (COTRI, China Outbound). Most of them like hiking and shopping. A competing destination for Chinese tourists is always Hong-Kong and Macao, where they go for hiking tourism. About 104 countries were the destinations of Chinese people. Male tourists outnumbered the female ones. It is expected that tourism for elderly Chinese tourists will develop soon. $74 \%$ of Chinese people thought that their travelling abroad was an important consumption decision. Visiting scenic spots is the most important reason for them to travel. 59\% of Chinese people travelled with duration for less than a week. They choose mid-priced, economy hotels $(70 \%) .51 .5 \%$ of Chinese tourists stated that their expenditures on purchased goods, while on holiday, cost more than their package tour fare. This reveals that they are good shoppers. Their projected consumption for future outbound travel is that $53 \%$ of them want to go sightseeing, $23 \%$ want to participate in entertainment activities, $13 \%$ of them want to go on expeditions and $10.5 \%$ to understand the living conditions of the local residents in the countries they visit (China Tourism Academy, 2010).

As far as the appeal that Greece makes to Chinese tourists is concerned, Greece belongs among the top 3 destinations in Wedding \& Honeymoon trips and competes with Maldives and Thailand and the top 10 outbound tourist destinations for Chinese people, according to Chinese Organization of Tourist development and an online survey 
conducted by the most popular social media corporation in China (Papadimopoulos, 2017). Chinese people are attracted by holidays in the Aegean islands and other places of archaeological interest. The English word 'Aegean' (which signifies the Greek sea of Aegean) has the same pronunciation in the Chinese language as the Chinese word for 'love'. This is one of the reasons that, there are many more tourist packages for the Aegean islands and not so many for Dodecanese islands, Crete, Ionia islands etc (Papadimopoulos, 2017).

In the Greek market which is already seething with tourists during the summer months, the advent of the high numbers of Chinese tourists (the figures have already been reported in the introduction) will crowd out the current clients at that period of the year. Tour operators will have to re-distribute Germans, English, Russian and Swedish tourists to other markets if Chinese tourists visit Greece. Unless new accommodation is built or the seasonality that characterises tourism in Greece is smoothed, Greece will suffer from over-tourism. Average annual hotel capacity is about $48 \%$, the highest being noted in Crete with $62 \%$, followed by the Ionian islands being 54\% in 2014 (Greek Statistical Agency, 2015).

Figure 1 International tourist arrivals to GREECE based on nationality (see online version for colours)

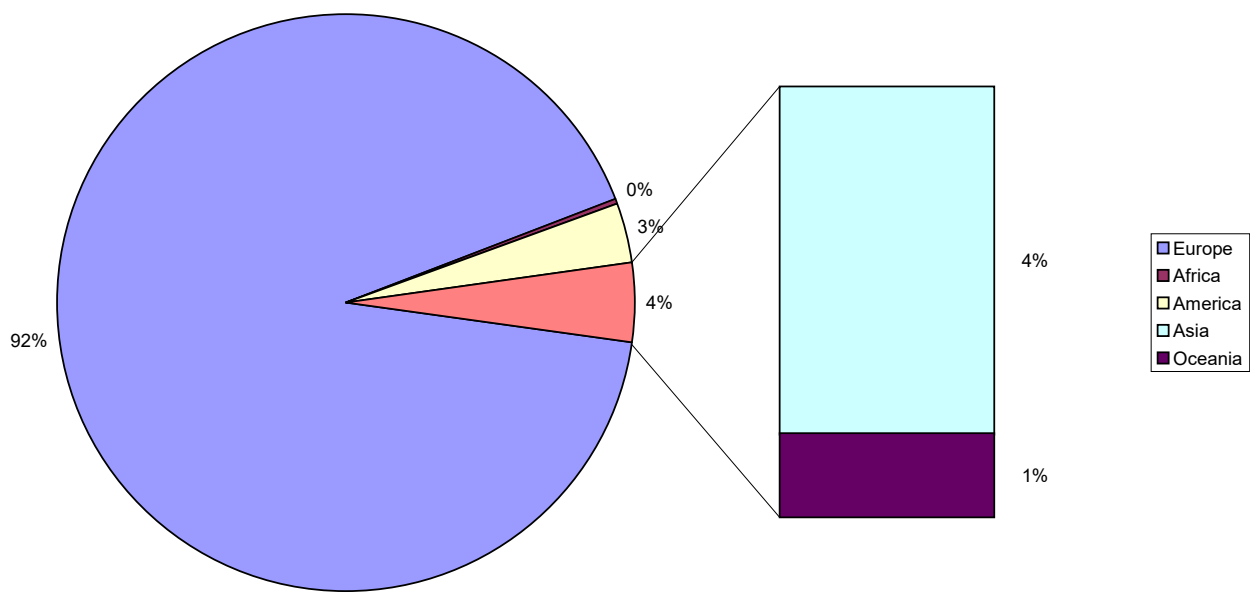

Source: Greek Statistical Agency (2015)

Based on Figure 1, the majority of tourist arrivals in Greece originate from Europe. The largest part of European tourists to Greece comes from Germany and UK. Other major parts of international tourism to Greece come from France, Russia, Italy, the Netherlands, Sweden, Norway, Switzerland, Poland, Austria, Belgium, Denmark, Romania, Czech Republic and Finland. From America, the largest part of tourist comes from the USA and less from Canada. As far as the Asian countries are concerned, only 18\% are Chinese tourists, $7 \%$ are Japanese and the rest comes from other Asian countries.

Based on the Greek total hotel capacity displayed in Table 1 and given that Greece has 806,045 beds, this means that if the sector works at full capacity round the year, namely for 365 days, then it can offer 806,045 beds $\times 365$ days $=294,195,475=$ guest nights. Also, under an aforementioned assumption that Chinese tourists make short holidays of one week length, then Greece could host 294,195,475/7=42,027,925 tourists 
which is about half of the current Chinese outbound tourism. The latter figure makes the assumption of complete crowding out of all other tourism nationalities round the year. In a more realistic scenario, with 3 months (mid June- mid September) assigned to tourists other than Chinese nationals and the rest of 9 months are assigned to Chinese tourists, this translates into Greek host capacity for 31.0 million Chinese tourists. To realise the class size of the aforementioned calculations, we need to remind that only $5 \%$ of Chinese people are outbound tourist travellers currently and growth in Chinese tourist outflows is a two digit number.

\section{A brief presentation of the Greek economy, environment, society and culture}

The presentation of the Greek economy and country will take place through a wide selection of indicators about all aspects of life in Greece. For a better understanding of these figures, we deem it worthwhile to compare them with the corresponding figures in China, because the best way to understand a foreign economy is through its comparison with one's own economy.

\subsection{General economy}

Greece is a small country with a surface of $131,957 \mathrm{~km}^{2}$ and a population of 10.75 million. In 1981, Greece entered the EU and in 2002 it adopted the euro currency. The Greek economy has been interrupted several times by wars in the past and only after the Second World War and the civil war which followed, has it stabilised. The GDP of the country was $€ 187.1$ billion in 2017, with $1.4 \%$ increase from 2016 and a public debt equal to $177.4 \%$ of its GDP. During the decade 1990-2000 Greeks have consumed more than they earned, due to cheap consumption loans provided by banks and the generous increases of salaries and pensions that the political system provided. At the same time, high production costs have driven most industries to move their production facilities abroad and significant parts of local population were driven to unemployment. Moreover, the organisation of the Olympic Games in 2003 cost a lot in public funds. The still pertinent tax-evasion and the bureaucratic public sector have not allowed the complete revival of the economy yet, which is relying heavily on tourism, shipping activities, manufacture and selective agriculture with a focus on small production of special agricultural products and delicatessen foods. Unemployment in Greece was about 22\% for 2017. The country could still benefit from further financial, tax and public sector reforms. The austerity programme after the beginning of the economic crisis has resulted in serious cuts in public expenditure, but these have saved funds which have not been injected to productive expenditure within the economy, but on paying back interests and loans.

Figure 2 enables a first comparison of the Chinese and the Greek economy. After 2000, the Chinese economy growth has stabilised with a few peaks, while the Greek economy has noted several downturns. This shows a first different perspective in the two economies. Furthermore, we will present next in Table 2, various aspects of the two economies with basic magnitudes which enable the understanding of the structural differences between the two economies and thus inform potential investors about the business environment in Greece. 
Figure 2 GDP growth of Greece and China between 1961 and 2015 (see online version for colours)

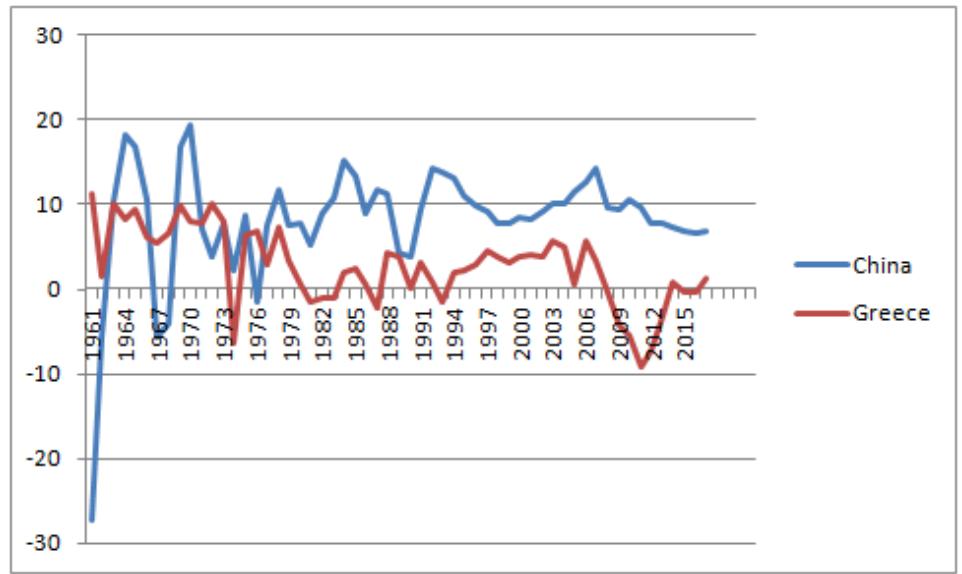

Source: World Bank (2017)

A brief overview of the Greek economy (juxtaposed to the Chinese) is presented in Table 2. Unemployment rate in Greece is high due to the economic crisis. Many job positions were lost when manufacturing and construction industries moved to other countries in the pursuit of low wages and taxes. Unemployment is lower in tourism destinations such as Crete, where for example this figure is 11.6\% (Cavalho, 2018). High unemployment has driven high-skilled Greeks to leave the country and work abroad. Inflation rose from $0.6 \%$ in May 2018, to $1 \%$ in June 2018. The driving sectors in this increase have been transport, food and non-alcoholic beverages. Inflation has eased in the hotel, cafes and restaurants, tobacco and alcoholic beverages. The cost of housing, recreation and cultures has also fallen.

As a member of the EU, the base interest rate in Greece is decided by the European Central Bank. The government debt has averaged about 100\% from 1980-2017 with the highest having reached in $180.80 \%$ of the GDP in 2016. Apparently, the Stock market in a country characterised by the particular economic conditions as those in Greece, the Stock Exchange idleness reflects that situation too with a low volume of transactions. Noteworthy is the difference in the GDP structure in Greece. Reported are GDP sections produced from mining and public administration in Greece, but these are not reported for China. Quite impressive are the labour numbers when juxtaposing the Greek high inflation with the Chinese almost full employment. However, minimum Greek wages are double the corresponding Greek ones and this explains the fact why industries have closed in Greece. On the other hand, manufacturing wages are high in China, with wages equal to more than 12 times the minimum Greek wages. This reveals both the importance of the sector and its specialisation as well as the size of wages received by high skilled staff. The rest of the Money and Business indicators reveal the existence of small differences between Greece and China. For example, the corruption index is only seven units higher in Greece than in China. The ease of business is perceived to be higher in Greece, although most taxes are higher in this country. The Business Confidence Index is also higher in Greece. So is the corporate tax and gasoline price. 
Table 2 Business economic indicators for Greece and China

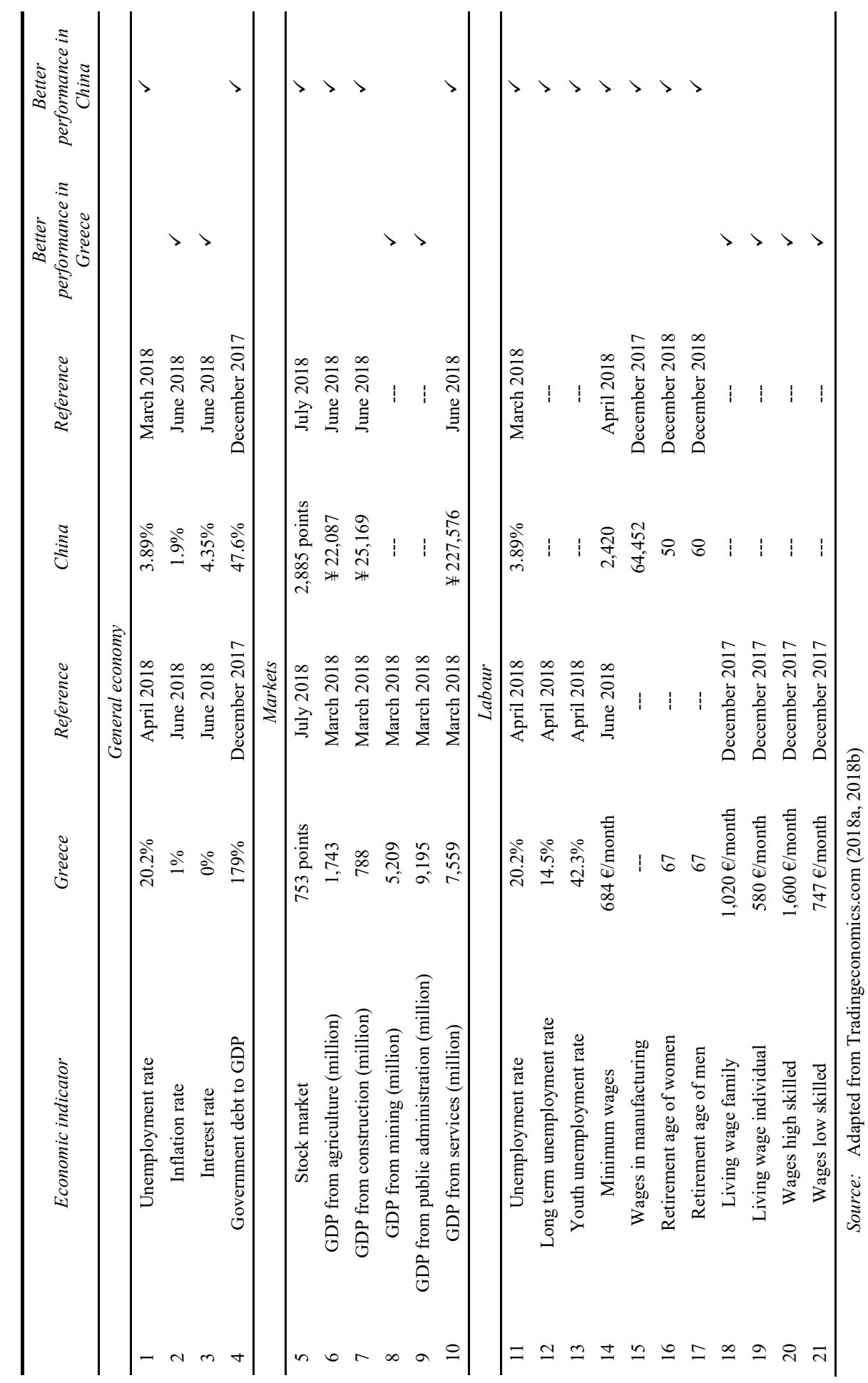


Table 2 Business economic indicators for Greece and China (continued)

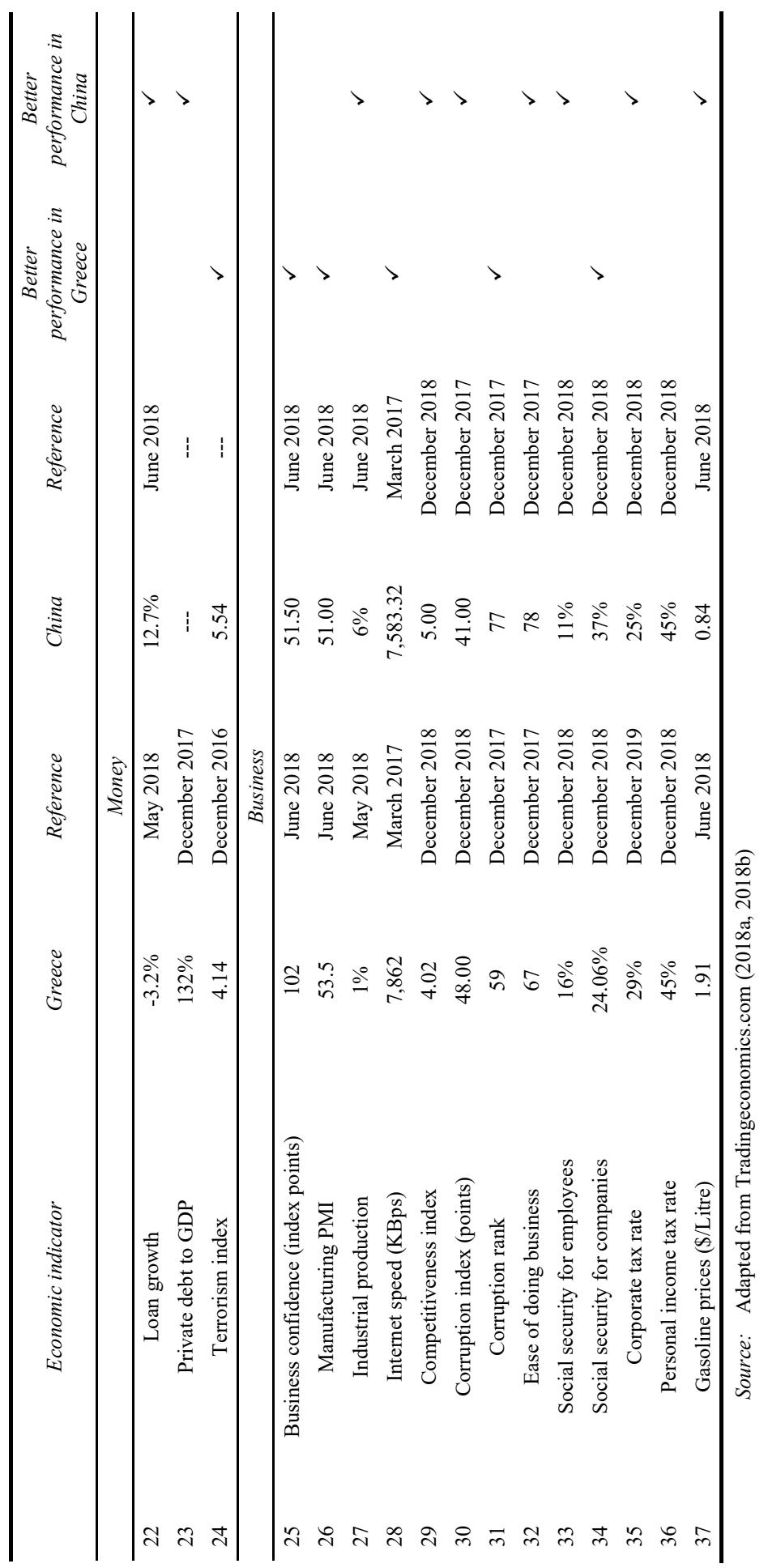




\subsection{Environment}

Greece has ratified major environmental agreements and as a member of the EU is obliged to conform to special environmental regulations. The greenhouse gas emissions (as percent change with base year=1990) have decreased considerably in the last few years, but the economic crisis afflicting Europe has also contributed to this direction. The comparison with China in Figure 3 reveals the high industrial development experienced by China and its subsequent high contribution to $\mathrm{CO}_{2}$ emissions.

Figure $3 \mathrm{CO}_{2}$ emissions as percentage from 1990 levels (see online version for colours)

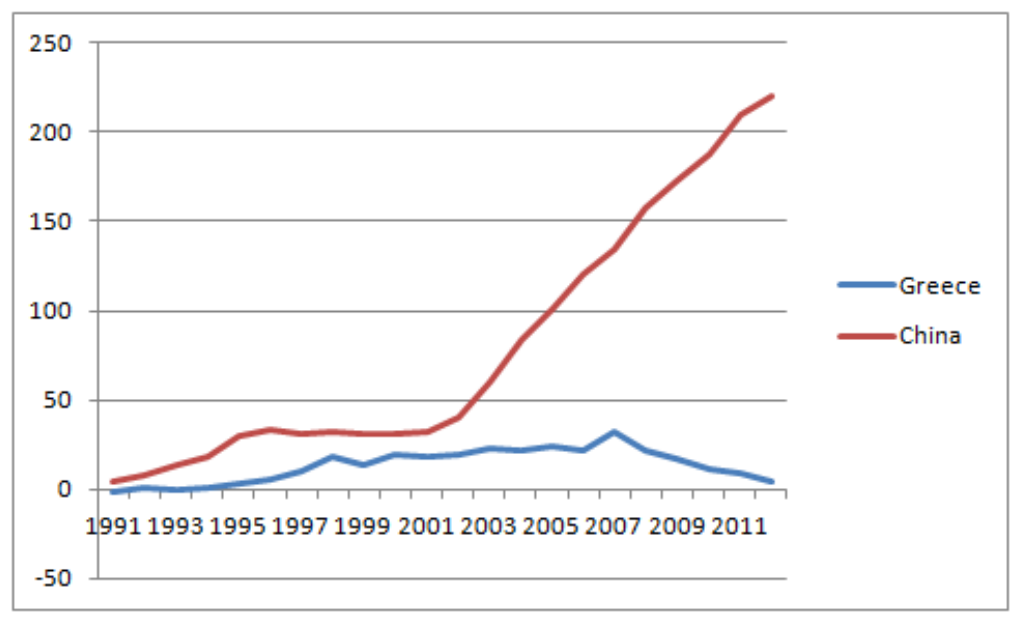

Source: World Bank (2017)

Greece has also made serious steps in renewable energy production and consumption. From 1990 it has followed an increasing tendency in this direction. Renewable energy consumption as percentage in final energy consumption was $7.81 \%$ in 1990 , slightly decreased in 2000 to $7.52 \%$ and increased again considerably in 2016 at $17.17 \%$. The opposite direction is followed for China which started with a renewable energy mix equal to $34.08 \%$ in final energy consumption, was lowered to $29.73 \%$ in 2000 and a much lower $12.41 \%$ in 2015 (World Bank, 2017). This tendency reflects the huge increases in energy demand in China as a result of increased industrial production, which is not the case in the economic crisis afflicted Greece. Both Greece and China reveal a turn to natural resource preservation since the index of natural resource depletion has improved in both countries from 1990 up to date. In Greece natural resource depletion (as a percentage to Gross National Income) was $0.11 \%$ in 1990 and improved to $0.038 \%$ in 2016. In China the relevant figure has been reduced from $5.10 \%$ to 0.679 in 2016.

Overall, it can be said that the environmental legislation is mature in Greece and there are increasingly many limitations that must be taken into consideration at the beginning and during the operation of a business. A business must take into account all necessary precautions not to contaminate the environment. Thus, it must contribute to sustainable development also abiding by the 'polluter pays' principle. The situation is more complicated, because this is combined with the shortage of explanatory regulations which are supposed to explain the imposition of law and the very slow and outdated Justice system in Greece. Also, reforms such as the completion of the national cadastre, research 
shortages and lack of monitoring systems and controls make the environmental compliance a not so easy process for the business to follow (WWF, undated).

\subsection{The Greek society and culture}

Greeks are Mediterranean people. They are loud and social. Family bonds are still strong in Greece and young people leave their parental home after their 30s (Christodoulou, 2018). To this situation also contributes the high youth unemployment, the low wages (pertinent after the economic crisis) and the high prices that make it hard for young people to establish their own household even if they find a job. An increasing number of people live together without getting married or they prefer signing an agreement of living together. Single parenting and the divorce rate are also on the increase. Only in 2018 was approved by law the wedding between people of the same sex, while the adoption of children by parents of the same sex is under discussion.

The educational system is based on state schools and universities, which are highly complemented by support private schools. The average Greek family is fond of the idea of sending their children to university and make them qualify for a position in the public sector and do not wish their children to be employed in manual jobs.

Greek culture has been shaped by both Eastern and Western influences. Thus, albeit Greece belongs to Europe, it bears a lot of Ottoman elements and habits in everyday life, its customs, music, food and language. Greek people are widely renowned for their hospitality and the tendency towards a healthy, balanced life between work, family and social life. During the last two decades though, this way of life tends to change and has adopted more globalised features. Working hours are longer and there is less time available for socialising and bonding, people are less co-operative to each other, they consume fast food etc. Religion does not play as an important role in modern Greek life as it did in the past. The majority of Greeks are Christian Orthodox in religion. However, due to large immigration rates towards Greece from Asian countries, currently, or Balkan countries in the recent past, there is also a part of Muslim population in the country.

\section{Dealing with the asymmetric information of the Chinese side}

Investors who are equipped with comprehensive information, are also confronted less with the uncertainty caused by asymmetric information. Embarking on a significant sized investment such as the vertical integration of a tourist business, presupposes investors being acquainted with the Greek economy, culture, tourism, the business environment, laws, institutions and various characteristics of the Greek economy and society.

\subsection{Greece has turned to quality, individualised experience tourism}

New trends have developed in the Greek tourism sector, which provide directions away from mass tourism and over tourism, while they pave the way towards quality and luxurious individualised tourism demand satisfaction. Through tourism, different nations can communicate. Mass tourism which aims at visiting as many museums and archaeological sites as possible, or participating in various forms of entertainment which 
sometimes are risky for human health and insulting for dignity. Alternative tourism or mild tourism could contribute to the nations' improvement of knowledge for each other's culture, religion and traditions. Mass tourism does not provide the opportunity of communication with the people of one country with the other. Agri-tourism is another promising type of tourism which contributes to the deeper understanding of other countries' people, mentality, natural resources and cultural heritage. Mass tourism provides tourists with food of poor quality and mass agricultural products which are poisoned with chemical fertilisers (Laiou-Antoniou, 2018).

Greek tourism aims at the experience tourists will gain from visiting Greece and not on the consumption expenditure. The new model of tourism development deviates from mass the homogeneous tourism product and aims to make tailor-made tourist products. Emphasis is also placed on luxurious tourism in which tourists will stay in villas and enjoy special activities. In Greece there is also scope for alternative forms of tourism such as health or therapeutic tourism. Greece has about 700 therapeutic water fountains, but very few specialised health resorts. According to Kalampokis (2017), this type of tourism is able to generate an annual revenue of about $€ 500$ million -1billion annually. There is also significant margin for the development of conference tourism, honeymoon tourism, medical tourism, particular forms of agricultural tourism such as wine tourism, oleo tourism and Airbnb opportunities. Despite the vast unconsumed potential of Greece in the tourist sector, the country is not competitive on the taxation framework it provides for investors.

Greece is among the 10 top tourist destinations in the world. Long experience in the tourist sector has led to the creation of knowledgeable and expert labour force. Greece hosts 9,370 hotels, is a country rich in culture, sea-costs, biodiversity and tourist attractions. It has 18 UNESCO World Heritage sites. This guarantees an increasing demand for accommodation in Greece and a lot of potential for the sector. Seasonality in Greek tourism means that there is a huge accommodation capacity which remains idle during the weekend and can be exploited for the development of outbound Chinese tourism, particularly since major Chinese holidays take place outside the peak tourist season. Greece is among the countries with high demand for holiday residences from international high income holders. Investors from Kuwait, Russia, Turkey have turned their attention to Greek tourist properties and they regard them as an asset for their portfolios (Belos, 2018). Based on the new Law 4531/2018, foreign strategic investors can be allotted the Greek nationality, when they invest an amount of money higher than $€ 500,000$ in Greece.

In Greece there are still many islands and inland regions which are not far from Athens and have not been developed touristically. Northern Greece for example has many low cost opportunities which can turn into valuable tourist asset opportunities, if developed and marketed in a balanced way that will not damage the ecologically protected areas. Currently, the low developed tourist regions attract tourists that are Greek residents or low income Balkan nationality tourists. Table 3 shows the popularity of Greek regions as tourist destinations. The lower demand in the third and fourth tier regions reveals the existence of hidden profit opportunities. The price level is lower in these areas and there is reasonably priced available land close to the sea and other natural landmarks. These areas are also more sparsely populated and there is no congestion from over tourism (Ifantis, 2017). 
Table 3 Ranking of Greek regions based on average tourist expenditure

\begin{tabular}{lcc}
\hline & Region & Average tourist expenditure $(€)$ \\
\hline First tier & Crete & 682.2 \\
& Ionian Islands & 611.9 \\
& Cycladic Islands & 600.0 \\
Second tier & Dodecanese islands & 600.0 \\
& Thessaly & 422.0 \\
& North Aegean & 398.6 \\
Third tier & Peloponnese & 383.7 \\
& Attica & 381.7 \\
& Epirus & 304.0 \\
& Sterea Ellada & 286.7 \\
Fourth tier & Western Greece & 283.5 \\
& Central Macedonia & 264.0 \\
& Eastern Macedonia and Thrace & 211.5 \\
\hline
\end{tabular}

Source: Adapted from Ifantis (2016)

Small hotels (which are very typical in Greece, but hide many opportunities for investors) are characterised by a weak management and promotion of their product, therefore tour operators play an important role in this matter (Bastakis et al., 2004). Also, small hotels are more vulnerable to criticism with respect to their lack of environmental protection measures. Small hotels do not have easy access to loans and cannot finance the necessary infrastructure improvement, which is necessary for the protection of the environment. Tour operators have a unique opportunity to establish and promote environmental conscious tourist accommodation and provide examples to the rest of the sector.

\subsection{Immigrant inflows to Greece}

Greek people are a nation who have been affected both by European and Ottoman civilisation. Most Greeks are Christian Orthodox in religion, but a Muslim minority lives in Northern Greece too. With the advent of numerous immigrants of Asian and African origin, there is a wider synthesis of religion groups living in Greece. The strong family bonds in Greece make Greek people feeling sentimentally attached to their land and property that belongs to their ancestors. However, the financial crisis has forced Greek people to sell property and change such attitudes. The fact that Greece is a country which offers some of the privileges of European life, while at the same time is a country with a looser institutional framework and a slower pace of life which is a characteristic of a Mediterranean country, has made it a beloved destination for immigrants.

The high inflow of immigrants towards Greece is not new. The tendency started in the 1990s. After the demolition of communist regimes in the Balkan and South-East European countries, a significant influx of Albanian and Bulgarian nationals have sought employment and settled down in Greece. These workers have been absorbed mostly in the agricultural sector. For about three decades, these workers were predominant in Greek agriculture and domestic cleaning sector. It is estimated that $90 \%$ of Greece's agriculture 
wage labourers are migrants and 7\% of the population in Greece are immigrants (census 2011).

Nowadays, there is also a clearly high influx of Asian immigrants to Greece. Migration of Asian origin peoples is a result of war conflicts and political persecutions. Illegal migration is easier in Greece, because of the large coastline and the numerous islands that belong to the country. Although Asian immigrants regard Greece as a transit country for their further movement to central Europe, international agreements and regulations prevent the advancement of immigrants to central Europe and thus the Greek state accommodates immigrants in various state establishments in an attempt to support them in their provisionary stay. Other state actions and measures are taken with the aim to absorb and assimilate these populations into the Greek society.

The advent of Asian immigrants is an unprecedented experience because their culture is much different from the European. In 1970s, the first Asian immigrants were Pakistanis who benefited from the signature of an inter-state agreement between Greece and Pakistan. In the 1980s a new wave of Asian immigrants was noted, with a significant number of Indians and fewer Bangladeshis, most likely due to the high expectations that were formed by the accession of Greece into the European Community. The improvement of the educational level of Greeks has led to their reluctance in doing unskilled jobs, which in turn were filled by Asian national immigrants. Asian immigrants are principally employed in agriculture, commerce, construction, industry and petrol stations.

Overall, Greeks are a nation that tolerates the difference imported by immigrants. After the economic crisis, nationalistic political parties have been empowered though. These parties express extreme ideas and attitudes towards foreign employees, but still the general tendency is that Greeks are a friendly and tolerant nation. However, the Greeks have since the establishment of the Greek state been regarded as an ethnocentric nation who speak the same language and have the same religion. The cultural diversion of immigrants have eroded this homogeneity and the emerging pluralism is contributing to the generation of a more open society which is gradually becoming accustomed to the generation of a new era of an integrative co-existence of Greeks with people of diverse nationalities, cultures, religions and backgrounds.

There are Chinese people who have immigrated to Greece not only for economic reasons, but also for their children receiving a better education or for better medical treatment. Yang (2017) also supports that food scandals and environmental degradation in China have led many Chinese people to decide to leave their country. In 2003, the number of Chinese shops has soared in Greece and the owners sent invitations for their families or other Chinese people to come to Greece and work for them.

\subsection{The Greek 'filotimo'}

The Greek 'filotimo' is a virtue whose word origin is ancient and it means love for the honour. 'Filotimo' is difficult to translate in other languages because it constitutes a complex of virtues. In Modern Greek the word refers to the ability of having a developed sense of responsibility, be generous, show zeal and passion for what one is doing, being persistent etc. A person is 'filotimos' if he/she possesses the aforementioned code of behaviour. The Greek 'filotimo' was a virtue that was discerned in Greek people because they were helpful and hospitable to foreign visitors in a disinterested way. 


\subsection{The Asian flu}

Because China is a densely populated country (population density is 148 people per square metre, juxtaposed to 83 people per square metre that applies in Greece, World Bank, 2017) which relies heavily on mass transport, occurrences of flu pandemics will bear a higher toll in such countries. The Avian Flu emerged in 1996-1997 in Hong-Kong and ended in large outbreaks in 2007 in poultry in almost 60 countries with several hundreds of human cases (WHO, 2007). The occurrence of the Avian Flu not only harms the image (as a tourist destination) of the country in which it breaks out, but also it harms a country, from a tourist consumer reservoir point of view. In the event of such an outbreak, China will damage both its inbound and outbound tourism.

\subsection{Terrorism and strikes}

In Europe have taken place various Muslim terrorist attacks in the last few years. According to research (Gazopoulou, 2011), these phenomena have a transitory impact on the tourist flows. Up-to-date none of these attacks has taken place in Greece. But if Greece suffered a terrorist attack, the cost from the lost tourist revenue would be considerable, given that tourism is an important share for Greek economy. However, given that about two thirds of the travel revenue comes from residents of the euro area, when these countries are hit by terrorist attacks, there might be contagion to Greece. European residents will be psychologically affected by such actions and may cancel their planned holidays. The reverse trend is noted when terrorist actions take place in Turkey and other countries of the Middle East or North Africa. The latter usually leads to increased bookings in Greece, which is close to these countries and is regarded as a substitute holiday destination. Given the tourist flows volatility with respect to terrorism, there are many impact scenarios that one can make.

As far as strikes are concerned: Strikes are common in a democratic country such as Greece. Since their aim is to attract the attention of politicians through the inconvenience and pressure they generate, strikes are not announced earlier than a week's time. They sometimes affect transport and this in turn can affect one's holidays. For their maximum result, strikes, particularly transport strikes, are also planned during holidays' peak time, because at that time they are expected to address pressure. One way through which tourists in Greece can protect the smooth implementation of their holidays, is through the selection of not so tight connections. Also, when tourists buy travel insurance, they can be compensated for such unforeseen circumstances. Last, another parameter that must be taken into account when travelling in the Greek islands is that sometimes, due to the wind, ferries stay in and do not perform their itineraries. Other frequent forms of strikes are those of garbage collectors. These cause mostly an aesthetic effect on some roads and squares which can remain littered for quite a few days, but they are not a real problem for holidays. Last, strikes affect the accessibility to some archaeological sites which are in the centers of cities, because of demonstrations taking place and usually they block access to the city centre.

\subsection{Foreign languages are spoken by Greek people}

The official language in Greece is Greek. Greek people however learn foreign languages and the most common of them are English, German, French and Italian. English is 
compulsory to learn at school. Also students have a compulsory elective between the French and German language. Lately, Greek people have started learning Spanish, Russian, Turkish and Chinese. However, these languages are usually learned for business reasons by professionals. While most young Greeks speak English, not all Greeks speak English. For example, the bureaucratic language remains Greek. Some government web-pages offer English page versions, but often these versions offer less or outdated information. On the other hand, the Greek language is generally acknowledged to be a difficult language. When Europeans do not understand a language, they say 'It is all Greek to me', but when Greek people do not understand a language they say 'It is all Chinese to me'.

\subsection{The flourishing BnB competes typical hotel lodging}

$\mathrm{BnB}$ is a competitor to the conventional hospitality sector. The concept behind $\mathrm{BnB}$ is the more novel individualised experience pursued in tourism. Airbnb travellers aim to get an authentic and local travel experience. Also, BnB is more environment friendly than large hotels. More than 100,000 homes in Greece have been registered in Airbnb. This business contributes $€ 69$ million revenue to the Greek economy yearly and supports about 1,000 jobs. According to a study in Athens, Airbnb guests stay on average 3.6 nights and spend $€ 551$ in their trip. In 2017, this sector had 1,370,000 arrivals in Greece from more than 150 countries with average income per host equal to $\$ 3,200$ and 28 night stays per home (Travel News, 2018). The number of the above mentioned arrivals has been deprived from conventional hotels. Thus, if conventional hotel owners aim to compete with BnB and recover that part of clientele, they need to provide individualised, authentic experiences with a significant taste of locality.

\subsection{The growing demand for sustainable tourism}

Sustainable tourism is one of the objectives of the EU and it has been found that tourists would be willing to pay higher prices for sustainable hotels. During a survey conducted in March 2017, 93\% of travellers from China stated that they were more likely to choose a hotel knowing that it was eco-friendly. This figure was $83 \%$ for Brazilian travellers, $80 \%$ for Spanish and $68 \%$ for the global average (Statista, 2018). Given that China has a comparative advantage in manufacture and commerce, it can focus on establishing the most efficient and cost-effective sustainable technologies that can be adopted in hotels in Greece. These hotels are not only the ones that will be vertically integrated by Chinese companies, but also the rest of the hotels in the sector that wish to incorporate these technologies. According to Maidment (2009), Chinese people are good at reducing costs but have not been able to add on the premium that can be charged on a top brand. Sustainable hospitality technologies are an opportunity for Chinese people to change this belief.

\subsection{The political risk}

We use the term political risk to refer to wars, revolutions and unrest, arbitrary government actions and government instability, which is manifested with frequent changes of government chief executive and key ministers. In this group of risks also fall the currency (exchange) shortages and natural disasters. According to the 
GlobalEconomy.com (2018), in a rating scale from 1 to 7, the average value for Greece from 2014-2017 was 5 index points. Currently there is the risk of snap elections in Greece, since the government is going through the fourth year in power and it is in the middle of various significant transformations in all sectors, as well as major issues in external and internal affairs. On the other hand, another type of risk is claimed very often and is that of triggering a premature exit from the extant bailout programme. According to GlobalEdge (2018), the risk assessment for Greece, either the country one or the business one, is at an acceptable level. This translates into that there are political and economic uncertainties, which may cause difficulties in the business environment and corporate payments. As far as the risk at business level is concerned, corporate financial data are not always available or reliable and debt collection is not an easy task. The financial support from international means and the possibility of debt relief could be regarded as positive elements for the economy. On the other hand, among the economy weaknesses are regarded the high debt and the social tensions caused by the austerity measures that are imposed to Greek taxpayers in order for the economy to build financial surpluses. Other weaknesses are the high tax evasion, the bank portfolio structure, the meager industry and fragile institutions.

\section{Conclusions}

There is a fast growing number of Chinese people travelling abroad for tourism purposes and Greece has currently received only a small share of them. More specifically, in 2012, about 82 million Chinese participated in outbound tourism, 3 million of them visited Europe and only 12,203 of them visited Greece. The numbers keep growing every year and are bound to explode given the fact that, currently, only $5 \%$ of the Chinese population possesses travel documents. These increasing numbers of Chinese tourists in Greece entail that Chinese tour operators will seek their space in this new and challenging market and will be confronted with asymmetric information. The paper discusses major opportunities as well as pitfalls that may be encapsulated in the vertical integration of Chinese tourist businesses in the Greek tourism sector. Important conclusions are derived, which can help Chinese businessmen prepare themselves. These are:

- First, Chinese vacations are short and fall in winter months. This facilitates smoothing out the high seasonality of tourism in Greece, which occurs in summer months and typically opens at the time of the Catholic Easter. This also will prevent crowding out other nationalities (Germans, Scandinavians, Russian and Americans) from tourism in Greece. Greek and Chinese policy makers can co-operate on this and distribute tourists smoothly throughout the year. Taking into account the available hospitality capacity and the soaring Chinese tourist numbers, we have made some rough calculations: Given that Greek hotels have 806,045 beds totally, this means that if the sector works at full capacity round the year, namely for 365 days, then it can offer 806,045 beds $\times 365$ days $=294,206,425=$ guest nights. Also, under an aforementioned assumption that Chinese tourists make short holidays of one week length, then Greece could host 294,206,425/7= 42,029,489 Chinese tourists yearly for a vacation with duration of one week. This is an equivalent of half of the current Chinese outbound tourism worldwide (Remember: Only 5\% of the current Chinese 
population participates in outbound tourism). The above calculated figure makes the assumption of complete crowding out of all other tourism nationalities round the year. In a more realistic scenario, with three months (mid June- mid September) assigned to tourists other than Chinese nationals and the rest of 9 months are assigned to Chinese tourists, this translates into Greek host capacity for 32 million Chinese tourists.

- Second, expansion of the hospitality capacity in Greece is possible given that there is a new ascending AirBnB sector in Greece currently. Also, there are old hotel buildings which can be rent or bought and renovated or new ones can be built. There are areas in Greece which have not received much attention from investors (such as North Greece and particularly Thrace). These areas have a lot of potential for development, land is cheap in those areas and local unemployment is high. Furthermore, North Greece offers holidaymakers the opportunity to stay in Greece, but also pay short visits to the close countries such as Bulgaria and Turkey. Thus the tourist based in that area can combine a bit of everything: sea, islands, nature and other countries too. The Greek ministry of external affairs welcomes investments and populations in North Greece, because this is a sparsely populated area of Greece and also the border to foreign countries which means that special care must be applied to the area.

- Third, Greek tourism has embraced the new tendency for sustainable tourism. As a European country, Greece is obliged to respect European environmental directives and thus special attention must be paid to the environmental interactions of the hotel business. The successful Chinese manufacture sector can contribute to the development and promotion of cost effective sustainable technologies for the hospitality sector.

- Fourth, Chinese investors have already made their successful business steps in Greece with the COSCO venture in the Piraeus port. They have also expanded in telecommunications, energy and real estate. A next step in tourism could greatly benefit from the inevitable agglomeration effects. Already, this has taken place to some extent with the flights from Beijing to Athens which transport tourists to Athens who are further embarked to cruises from Piraeus port towards Europe. This transit opportunity can be extended and help Chinese tourists combine more European destinations in one visit, thus reducing cost and enjoying economies of scale.

- Fifth, there are cultural, political and social issues that need to be overcome between the Chinese and Greek people. The current paper analyses these issues and equips Chinese businessmen with useful and insightful comparisons of the Greek economy, environment and society with the Chinese corresponding ones. Both societies are open to business and thus there is potential for compatible co-existence.

- Last, following the COSCO venture and its spectacular success in Greece and worldwide, we think that Chinese tourism policy makers will need an analogue administration vehicle to overcome difficulties and minimise asymmetric information risks. 


\section{References}

Bastakis, C., Buhalis, D. and Butler, R. (2004) 'The perception of small and medium sized tourism accommodation providers on the impacts of the tour operators' power in eastern Mediterranean', Tourism Management, Vol. 25, No. 2, pp.151-170.

Belos, E. (2018) International Elite Buys Holiday Residences in Greece [online] http://www.kathimerini.gr/946724/article/oikonomia/ellhnikh-oikonomia/e3oxiko-sthn-elladaagorazei-h-die8nhs-elit (accessed 15 July 2018).

Cavalho, L. (2018) Greek Jobless Rate Edges Up to 20.2\% in April, ELSTAT [online] $\mathrm{http}$ //tradingeconomics.com/Greece/unemployment-rate (accessed 26 July 2018).

China Tourism Academy (2010) Annual Report of China Outbound Tourism Development 2009/2010 [online] https://books.google.gr/books?id=HUMpHEtJX40C\&pg=PA114\&lpg= PA1 14\&dq=China + tourism + academy+annual + report + of + china + outbound + tourism + develop ment $+2009 / 2010 \&$ source $=$ bl\&ots=7QpQ9DiMb0\&sig=juH2ckYzvYdiR5SvzBkBATbm7NI\& $\mathrm{hl}=\operatorname{tr} \& \mathrm{sa}=\mathrm{X} \& \mathrm{ved}=2 \mathrm{ahUKEwjhifrrl}$ reAhUPJ1AKHVFID4YQ6AEwB3oECAEQAQ\#v=onep age \&q=China $\% 20$ tourism $\% 20$ academy $\% 20$ annual $\% 20$ report $\% 20$ of $\% 20$ china $\% 20$ outbound $\%$ 20tourism\%20development\%202009\%2F2010\&f=false (accessed 3 June 2018).

Christodoulou, K. (2018) In Which Age do Europeans Leave Parental Home? Who Does this Later than the Greeks (title translated from Greek) [online] https://www.news247.gr/koinonia/sepoia-ilikia-afinoyn-ta-paidia-to-patriko-toys-stin-eyropi-poioi-xepernoyn-toysellines.6615981.html (accessed 8 August 2018).

Cooper, C., Scott, N. and Kester, J. (2006) 'New and emerging markets', in Buhalis, D. and Costa, C. (Eds.): Tourism Business Frontiers, Elsevier, London.

ECTAA.org (2016) The European Travel Agent's and Tour Operators' Associations [online] http://www.ectaa.org/files/cms/ad17-085-448.pdf (accessed 3 June 2018).

Eurostat (2018) Tourism Statistics [online] http://www.ec.Europa.eu/eurostat/documents/4031688 (accessed 4 June 2018).

Fan, P.H.J., Huang, J., Morck, R. and Yeung, B. (2017) 'Institutional determinants of vertical integration in China', Journal of Corporate Finance, Vol. 44, pp.524-539.

Fortune.Greece (2016) The Largest Hotel Chain in the World has Been Born, in Greek [online] http://www.fortunegreece.com/article/i-megaliteri-xenodochiaki-alisida-tou-kosmou-inegegonos/ (accessed 2 July 2018).

Gazapoulou, H. (2011) Assessing the Impact of Terrorism on Travel Activity in Greece, Working Paper 127, Bank of Greece

GlobalEconomy.com (2018) Greece: Political Risk, Long-Term [online] http://www.theglobaleconomy.com/Greece/political_risk_long_term (accessed 26 July 2018).

GlobalEdge (2018) Greece: Risk Assessment [online] http:/globaledge.msu.edu/countries/ Greece/risk (accessed 26 July 2018).

Greek Statistical Agency (2015) International Tourist Arrivals to Greece, Based on Nationality [online] http://www.statistics.gr/documents/20181/301069/GreeceInFigures_2015Q3_EN.pdf (accessed 6 July 2018).

Hellenic Institute of Tourist Research and Forecasting (2018) Hotel Capacity in Greece [online] http://www.grhotels.gr/GR/BussinessInfo/library/DocLib/Hotels_Total-Country_2018.pdf (accessed 1 March 2018).

Hinsdale, M. (2018) 'Can Greece handle the coming wave of Chinese tourists?', Jing Travel 5 June 2018 [online] https://jingtravel.com/can-greece-handle-the-coming-wave-of-chinese-tourists/ (accessed 31 July 2018).

Ifantis, P.D. (2017) Tourism: Which Regions Have Generated Most Revenue?, in Greek [online] http://www.euro2day.gr/news/economy/article/1541759 (accessed 15 July 2018)

Kalampokis, T. (2017) The Future of Tourism in Greece [online] http://www.capital.gr/meapopsi/3257729 (accessed 15 July 2018). 
Kolasa-Sikiaridi, K. (2016) Greece Looks to 500,000 Chinese Tourists to Boost 2016 Season [online] https://greece.greekreporter.com/2016/07/08/greece-looks-to-500000-chinese-tourists -to-boost-2016-season/ (accessed 31 July 2018).

Konsolas, I. (2002) 'The competitive advantage of Greece, an application of porter's diamond', Routledge Revivals, p.190.

Kostopoulou, S. (2017) Meeting 'Civilization and Tourism for the Economic Development and Economic Crisis Solution [online] https://culturecrises.weebly.com/ (accessed 1 July 2018).

Laiou-Antoniou, C. (2018) The Future of Tourism, in Greek, To Vima, 15 August [online] https://www.tovima.gr/2008/11/24/opinions/to-mellon-toy-toyrismoy/ (accessed 5 June 2018).

Lin, V.S., Liu, A. et al. (2015) 'Modeling and forecasting chinese outbound tourism: an econometric approach', Journal of Travel and Tourism Marketing, Vol. 32, Nos. 1-2, pp.34-49.

Maidment, P. (2009) The Next Wave from China [online] https://www.forbes.com/consent/ ?toURL=https://www.forbes.com/2009/12/23/volvo-geely-ford-business-autos-china.html (accessed 3 July 2018)

Majendie, A. (2018) Chinese Tourists are Taking Over The Earth, One Selfie at a Time, Bloomberg 11 February [online] https://www.bloomberg.com/news/features/2018-02-11/chinese-touristsare-taking-over-the-earth-one-selfie-at-a-time (accessed 31 July 2018).

Papadimopoulos, T. (2017) The Chinese Tourist Market. The Picture, the Common Cultural Elements and its Dynamics, in Greek [online] http://www.epixeiro.gr/article/3316 (accessed 3 July 2018).

Pham, T.D., Nghiem, S. et al. (2017) 'The determinants of Chinese visitors to Australia: a dynamic demand analysis', Tourism Management, December, Vol. 63, pp.268-276.

Skivalou, M. and Filippidi, M. (2015) 'Chinese tourism: development and prospects for Greece', Tourism and Hospitality Research, Vol. 17, No. 3, pp.1-11.

Skordas, A. (2018) Chinese Tourists to Greece set to Double in 2018 [online] https:/greekcitytimes.com/2018/05/31/chinese-tourists-to-greece-set-to-double-in-2018/ (accessed 31 July 2018).

Statista (2018) Number of Hotels and Similar Accommodation in Greece from 2006 to 2016 (in 1000s) [online] https://www.statista.com/statistics/613678/number-of-hotel-and-similaraccomodation-greece (accessed 30 May 2018).

Tradingeconomics.com (2018) Greece - Economic Indicators [online] http://tradingeconomics.com/greece/indicators (accessed 28 July 2018).

Tradingeconomics.com (2018a) China - Economic Indicators [online] http://tradingeconomics.com/greece/indicators (accessed 28 July 2018).

Travel News (2018) Data for Airbnb in Greece for 2017, in Greek [online] http://www.etravelnews.gr/stoiheia-airbnb-gia-ellada-2017 (accessed 26 July 2018).

TUI Group (2017) Annual Report 2017 [online] http://www.annualreport2017/tuigroup.com/ finance/tui-group-2017-in-numbers (accessed 6 July 2018).

TUI Report (2017) Annual Report 2017 [online] https://www.tuigroup.com/damfiles/ default/tuigroup-15/en/investors/6_Reports-and-presentations/Reports/2017/TUI_AR_2017. pdf-7661895445c56eebea39a5b74aa9e5b3.pdf (accessed 1 June 2018)/

Untong, A., Ramos, V. et al. (2015) 'Tourism demand analysis of Chinese arrivals in Thailand', Tourism Economics, Vol. 21, No. 6, pp.1221-1234.

Untong, A., Ramos, V., Kaosa-Ard, M. and Rey-Maquieira, J. (2015) 'Tourism demand analysis of Chinese arrivals in Thailand', Tourism Economics, Vol. 21, No. 6, pp.1221-1234.

Vanhove, N. (2018) The Economics of Tourism Destinations, Theory and Practice, 3rd ed., Routledge, New York.

World Bank (2017) World Development Indicators [online] https://data.worldbank.org/products/wdi (accessed 20 July 2018). 
World Health Organization (WHO) (2007) Cumulative Number of Confirmed Human Cases for Avian Influenza A(H5N1) Reported to $W H O$ [online] http://www.who.int/influenza/human animal_interface/EN_GIP_201503031cumulativeNumberH5N1cases.pdf (accessed 2 February 2018)

WWF (undated) The Environmental Legislation and its Enforcement in Greece [online] http://www.wwf.gr/images/pdfs/InductionPack_EnvironmentalLawWWF.pdf (accessed 9 July 2018).

Yang, J. (2017) Legal and Illegal Chinese Immigrants in Greece, Status, Stores, Narratives from a Fieldwork in Thessaloniki, MA in Politics and Economics of Contemporary Eastern and South-Eastern Europe, University of Macedonia [online] https://dspace.lib.uom.gr/ bitstream/2159/21579/4/YangJieMsc2018.pdf (accessed 23 July 2018).

\section{Notes}

1 In 2010: 13,620, 2011: 15,838, 2012: 12,203, 2013: 28,000 and 2014: 47,482, 2015: 55,097 (Hinsdale, 2018), 2016: 150,000 (Kolasa-Sikiaridi, 2016), 2017: 170,000 and a projected number for 2018 being by 50\% increased compared to 2017 (Hinsdale, 2018). 